\title{
Estudo da capacidade de adsorção de carvões ativados comerciais versus tempo de armazenamento
}

\author{
Study of adsorption capacity of commercial activated carbon versus storage time
Helen Caroline Valter Fischer ${ }^{\mathrm{I}}$, Liliane Schier de Lima ${ }^{\mathrm{II}}$, Maria Lurdes Felsner ${ }^{\mathrm{III}}$, Sueli Pércio Quináia ${ }^{\mathrm{II}}$

\begin{abstract}
Resumo
O carvão ativado pulverizado quando bem embalado e estocado não possui um prazo de validade regulamentado. Em geral, esta validade é determinada de acordo com requisitos estabelecidos pelo próprio fabricante e está diretamente relacionada a uma estimativa de tempo superior ao tempo em que o produto ficará estocado no cliente até a sua utilização. Neste trabalho, avaliou-se a eficiência de carvões ativados de base seca e umectados, relacionando parâmetros de capacidade adsortiva (índice de iodo e umidade) destes materiais com o tempo. Os carvões contendo superfície alcalina não apresentaram variação nos parâmetros avaliados ao longo do tempo de armazenamento, pois não apresentaram significância estatística, uma vez que os valores de $F_{\text {regressão }}<F_{\text {critico }}$ e os valores de $p>0,05$, tanto para base seca como úmida. Dos carvões com caráter ácido ( $\mathrm{pH}$ corrigido), apenas um tipo foi mais sensível à adsorção de umidade e iodo ao longo do tempo. A partir da equação de reta oriunda da análise de regressão linear para este carvão, obteve-se a correlação Índice de Iodo $=824-0,370 \times$ dias, indicando que o tempo de armazenamento para este material foi igual a 605 dias, garantindo que o valor do índice de iodo seja igual ao valor limite de $600 \mathrm{mg} \mathrm{I}_{2} \mathrm{~g}^{-1}$ carvão.
\end{abstract}

Palavras-chave: Carvão vegetal; Índice de iodo; Umidade; Prazo de validade

\begin{abstract}
The pulverized activated carbon, when well packed and stored, doesn't have either a regulated or approved shelf life. In general, this expiration date is determined based on the established requirements coming from the manufacturer itself and it is directly related to an overestimation of the time that the product is held in the customer storage location until its use. In this analysis, the research has assessed the efficiency of the moistened and the dry activated carbon powder, relating parameters of adsorption capacity (numbers of iodine and humidity) in these materials with time information. The charcoals containing alkaline surface didn't exhibit a variation in the parameters evaluated along the storage time, since they didn't feature statistical significance, once the $F_{\text {regression }}<F_{\text {critical }}$ and the rate of $p>0.05$, both for dry and wet basis. From the viewed acid carbons (with corrected $\mathrm{pH}$ ), there was only one which got sensitive to moisture and iodine adsorptions over time. From the equation of the line originated by analysis of regression for this charcoal, the following correlation was obtained: Iodine Index $=824-0.370 x$ days, showing that the storage time for the carbon was equal to 605 days, assuring that the right value of iodine index is equivalent to the limit of $600 \mathrm{mg} \mathrm{I}_{2} \mathrm{~g}^{-1}$ carbon.
\end{abstract}

Keywords: Charcoal; Iodine index; Moisture; Expiration date

\section{Introdução}

O Carvão Ativado (CA) é um material constituído de carbono caracterizado por sua grande capacidade de adsorção, devido à porosidade elevada dada através da ativação do carvão geralmente realizada pela queima a uma temperatura de $800^{\circ} \mathrm{C}$ a $1000^{\circ} \mathrm{C}$, em um ambiente de

\footnotetext{
Química, graduanda em Lic., Universidade Estadual do Centro-Oeste, Alameda Élio Antonio Dalla Vecchia, 838, Vila Carli, CEP 85040-167, Guarapuava (PR), Brasil. helencarolinev@hotmail.com (ORCID: 0000-0002-3473-8367)

Química, Dr …, Alphacarbo Industrial Ltda., Estrada Municipal Benedito de Paula Louro, s/n BR277 - KM 342, CEP 84100-970, Guarapuava (PR), Brasil. liliane@alphacarbo.com.br (ORCID: 0000-0002-7759-5423)

III Química, Drª -., Professora do Laboratório de Análise de Traços e Instrumentação, Universidade Estadual do Centro-Oeste, Alameda Élio Antonio Dalla Vecchia, 838, Vila Carli, CEP 85040-167, Guarapuava (PR), Brasil. mlfelsner@gmail.com (ORCID: 0000-0002-7938-8399)

spquinaia@unicentro.br (ORCID: 0000-0002-1485-1063)
} 
oxidação controlado (ALLEN \& WHITTEN, 1998; SHAMSUDDINA et al., 2016; DE ARRUDA et al., 2017). Possui uma área de superfície que pode variar de $500 \mathrm{~m}^{2} / \mathrm{g}$ a $3000 \mathrm{~m}^{2} / \mathrm{g}$ de acordo com a matéria-prima utilizada e o método de ativação do carvão (AWWA,1996).

O uso de CA como adsorvente é empregado em diversas áreas. Seu uso como tratamento para a desintoxicação vem sendo utilizado desde os povos da antiguidade, pelos egípcios, hindus e gregos (WEST, 2008). No meio industrial, seu uso na adsorção de gases e líquidos vem demonstrando grande aumento, principalmente no tratamento de água. Estudos demonstram que o CA possui capacidade de adsorção até no tratamento de água com resíduos radioativos (EATON et al., 2005; KOSAKA et al., 2012; YAKOUT \& SHARAF EL-DEEN, 2016).

O carvão ativado pode ser comercializado tanto granulado, como pulverizado, e ainda na forma de briquetes (DEIANA et al., 2004). O CA granulado é utilizado predominantemente como adsorvente de gases por possuir o tamanho de poros superior ao pulverizado, podendo ser empregado também em líquidos como filtro, se atentando ao tempo de contato do líquido com o CA, uma vez que é necessário neste caso um tempo maior para a adsorção. O CA pulverizado por sua vez, é empregado no tratamento de líquidos através da mistura direta com o mesmo, sendo separado posteriormente através de métodos de separação, como, centrifugação, filtração, etc. Ambos os tipos de carvão auxiliam na remoção de cor, cheiro, gosto e demais impurezas (HUNG et al., 2005).

Por se tratar de um produto inerte, o carvão ativado quando bem embalado e armazenado não possui prazo de validade regulamentado, uma vez que nestas condições está isolado do contato com a umidade do ar ou outros produtos químicos que possam ser adsorvidos ou ainda que possam oxidar a superfície do produto. Em geral, esta validade é determinada de acordo com requisitos estabelecidos pelo próprio fabricante e está diretamente relacionada a uma estimativa de tempo superior ao tempo em que o produto ficará armazenado no cliente até a sua utilização. Contudo, em alguns processos de produção adicionam-se ao carvão alguns aditivos, como por exemplo, o ácido fosfórico, usado para a correção do $\mathrm{pH}$, e a água, que é usada na produção dos carvões ativados umectados, e não é de conhecimento da indústria o efeito destes aditivos ao longo do tempo na eficiência dos carvões ativados e por consequência no prazo de validade destes. Este trabalho teve o objetivo de avaliar a eficiência de carvões ativados umectados (40\%), relacionando parâmetros que avaliem a capacidade adsortiva destes materiais com o tempo, e realizar uma comparação destes com os carvões ativados com umidade padrão $(8,0 \%)$ e com os carvões ativados com o aditivo ácido fosfórico.

\section{Material e método}

Para este estudo utilizaram-se quatro tipos diferentes de carvão ativado vegetal provenientes de resíduos de reflorestamento de pinus (P) e de casca de coco de babaçu (CCB), dentro das especificidades contidas na Tabela 1 . Todas as amostras foram processadas por ativação física, isto é, usando vapor de água a temperaturas elevadas. O carvão W610 é um carvão seco com caráter alcalino, o WU610 é o mesmo carvão alcalino umectado ( 40 \%), o carvão LA possui caráter ácido com alto índice de adsorção, enquanto que o carvão 5630 possui caráter ácido (pH corrigido com a adição de ácido fosfórico) e granulometria superior aos demais. A amostra W610 foi armazenada em recipientes diferentes, a fim de avaliar os frascos de estocagem na qualidade de armazenamento dos carvões. Para diferenciá-los, denominou-se de W610ea (embalagem amostral), para a amostra contida no recipiente de contraprovas e W610ep (embalagem padrão) para o carvão armazenado a condições iguais às da comercialização (sacas de $25 \mathrm{~kg}$ ). Além da diferença de embalagem, os ambientes de armazenamento não foram os mesmos. O frasco de contraprovas ficou estocado em ambiente com umidade e temperatura controladas por ar-condicionado, enquanto que a embalagem pronta para comercialização ficou estocada em um galpão com presença de partículas pulverizadas de carvão no ambiente. Esses carvões foram produzidos em abril de 2018. Duas outras amostras do carvão W610 e WU610, produzidas em junho de 2017, também foram avaliadas. Todas as amostras 
foram cedidas pela empresa Alpha Carbo Industrial Ltda.

Tabela 1 - Características das amostras de carvões ativados pulverizados.

Table 1 - Characteristics of pulverized activated carbon samples.

\begin{tabular}{lcccccc}
\hline Código do carvão & Fabricação & $\begin{array}{c}\text { Matéria } \\
\text { prima }^{*}\end{array}$ & Iodo $(\mathbf{m g} / \mathbf{g})$ & $\begin{array}{c}\text { Umidade } \\
(\%)\end{array}$ & $\begin{array}{c}\text { \# 325 passagem } \\
\text { mínima }(\%)\end{array}$ & pH \\
\hline LA & & $\mathrm{P}$ & 831,1 & 6,5 & 90 & $5,5-7,0$ \\
W610 ea & & $\mathrm{P}+\mathrm{CCB}$ & 677,7 & 8,4 & 90 & Alcalino \\
W610 ep & Abril 2018 & $\mathrm{P}+\mathrm{CCB}$ & 697,9 & 6,5 & 90 & Alcalino \\
WU610 & & $\mathrm{P}+\mathrm{CCB}$ & 726,0 & 45,8 & 90 & Alcalino \\
S630 & & $\mathrm{P}$ & 728,2 & 6,9 & $50-65$ & $5,5-7,0$ \\
\hline W610 ep & \multirow{2}{*}{ Junho 2017 } & $\mathrm{P}+\mathrm{CCB}$ & 508,4 & 9,0 & 90 & Alcalino \\
WU610 & & $\mathrm{P}+\mathrm{CCB}$ & 672,1 & 32,2 & 90 & Alcalino \\
\hline
\end{tabular}

${ }^{*} \mathrm{P}$ (pinus); CCB (casca de coco de babaçu)

Para avaliar a capacidade de adsorção dos carvões utilizou-se o método de determinação do índice de iodo segundo a Norma MB-3410 (ABNT, 1991 a). O número de iodo é um teste muito utilizado comercialmente pelos produtores de carvão ativado, e determina o relativo nível de ativação dos carvões pela adsorção de iodo no carvão contido em uma solução aquosa. O método baseia-se na obtenção da quantidade de iodo absorvido, por grama de carvão ativado, quando a concentração do filtrado residual for $0,02 \mathrm{~mol} \mathrm{~L}^{-1}$. A partir do número de iodo tem-se a relação de porosidade do carvão ativado e a aproximação da área superficial do carvão. A padronização da solução de tiossulfato de sódio $0,1 \mathrm{~mol} \mathrm{~L}^{-1} \mathrm{e}$ da solução de iodo $0,1 \mathrm{~mol} \mathrm{~L}^{-1}$ foram realizadas diariamente, buscando-se minimizar os erros sistemáticos.

Medidas de umidade foram realizadas por análise termogravimétrica, na qual a umidade é calculada através da diferença do peso da amostra de carvão antes e após secagem em uma temperatura de $160^{\circ} \mathrm{C}$, com uma margem de erro de 0,01 \% (ABNT, 1991b). Para os carvões ácidos utilizou-se a análise de $\mathrm{pH}$ conforme indica o método ISO 10523 de 2008, com o auxílio de um pHmêtro devidamente calibrado. O monitoramento da qualidade das amostras de carvões produzidas em abril de 2018 foi realizado entre o período de 17 de abril à 21 de dezembro de 2018.

Para verificar se havia uma relação funcional entre os valores de índice de iodo e o tempo de armazenamento dos carvões uma análise de regressão linear simples foi aplicada no nível de 95\% de confiança. Considerando que os teores de umidade dos carvões podem afetar os valores de índice de iodo, análises de correlação linear de Pearson entre estas variáveis foram realizadas no mesmo nível de significância. Para verificar se haviam diferenças na absorção de umidade durante o armazenamento dos carvões W610ea e W610ep foi aplicado um teste- $t$ pareado, também no mesmo nível de confiança. Toda a análise estatística dos dados foi realizada com o auxílio do software Minitab for Windows versão 16.2.2.

\section{Resultados e discussão}

A Tabela 2 apresenta os valores médios, máximos e mínimos dos parâmetros índice de iodo e umidade para os carvões produzidos em 2018, medidos diariamente entre o período de estudo (240 dias). Observou-se que a média geral obtida para as cinco amostras de carvões variou 
entre 663,07 a 789,97 $\mathrm{mg} \mathrm{I}_{2} \cdot \mathrm{g}^{-1}$, valores estes superiores ao índice de iodo mínimo considerado ideal para a comercialização de um carvão ativado, que deve ser superior a $600 \mathrm{mg} \mathrm{I} \mathrm{I}_{2} \cdot \mathrm{g}^{-1}$ (ABNT, 1991c). Quanto ao valor máximo de umidade nos carvões pulverizados, utilizado na adsorção de impurezas no tratamento de água para abastecimento público, a norma EB-2133 estabelece o valor máximo de 8,0 \% (ABNT, 1991c). Dependendo da aplicação do carvão pulverizado, esse valor de umidade pode variar de 10 a $40 \%$, tendo a característica única de ser antidispersivo de pó, ideal para ambientes que necessitam estar limpos, como empresas de saneamento e indústrias alimentícias.

Tabela 2 - Valores de índice de iodo e umidade para as amostras de carvão ativado (produção 2018).

Table 2 - Iodine and moisture index values for activated carbon samples (production 2018).

\begin{tabular}{lcccccc}
\hline Carvão & \multicolumn{3}{c}{$\begin{array}{c}\text { Índice de iodo } \\
\left(\mathbf{m g ~ d e ~}_{\mathbf{2}} \cdot \mathbf{g}^{-1}\right)\end{array}$} & & \multicolumn{3}{c}{$\begin{array}{c}\text { Umidade } \\
(\% \text { em massa })\end{array}$} \\
\hline & Média & Maior valor & Menor valor & Média & Maior valor & Menor valor \\
\hline LA & 789,97 & 841,58 & 751,14 & 7,03 & 13,88 & 3,59 \\
W610 ea & 684,18 & 706,13 & 612,28 & 9,04 & 9,73 & 8,00 \\
W610 ep & 707,38 & 759,52 & 634,37 & 7,92 & 8,72 & 6,51 \\
WU610 & 663,07 & 726,05 & 622,32 & 44,67 & 45,87 & 42,84 \\
S630 & 702,87 & 755,80 & 661,56 & 7,28 & 10,49 & 6,52 \\
\hline
\end{tabular}

De acordo com LIMA et al. (2014), carvões provenientes de pinus apresentam grupos ácidos $\left(0,579 \mathrm{mEq} \cdot \mathrm{g}^{-1}\right)$ e básicos $\left(0,437 \mathrm{mEq} \cdot \mathrm{g}^{-1}\right)$ em sua superfície, enquanto os carvões de origem da casca do coco de babaçu apresentam apenas grupos básicos $\left(0,693 \mathrm{mEq} \cdot \mathrm{g}^{-1}\right)$. Por esses motivos, a mistura desses dois carvões, como visualizado nas amostras W610ep, W610ea e WU610, apresentam caráter alcalino (Tabela 1). Com relação ao diâmetro médio de poros, os dois carvões (P e CCB) são muito próximos, 5,225 e 5,375 Å, respectivamente, indicando que apresentam boa capacidade de adsorção (LIMA et al., 2014). A amostra LA, carvão ácido proveniente de pinus, demonstrou maior valor médio de índice de iodo quando comparado aos demais carvões. Com relação ao teor de umidade, a média (7,03 \%) apresentou-se dentro do padrão exigido para comercialização, no entanto, observa-se uma variação significativa entre as análises durante o período. Uma análise de regressão linear foi realizada considerando os teores de umidade do carvão LA mensurados durante o período avaliado. Esta mostrou valores de $F_{\text {regressão }}=337,7$ e de $p=$ 0,000 os quais são muito superiores aos valores críticos $\left(F_{\text {crítico }(0.05 ; 1,76)}=4,00\right.$ e $\left.p=0,05\right)$. Desta forma, pode-se sugerir que há um aumento significativo dos teores de umidade do carvão LA ao longo do tempo de armazenamento como pode ser visualizado pela equação de reta (umidade $(\%)=5,17$ $( \pm 0,15)+0,0309( \pm 0,0017) \times$ dias $)$.

As amostras S630 e W610ep também permaneceram com a umidade abaixo de 8,0 \%, enquanto que a amostra W610ea, apresentou resultados acima de $8,0 \%$. O carvão umectado (WU610) apresentou 44,67 \% de umidade, com pequena variação das medidas no período investigado. Como foram realizadas medidas em um grande intervalo de tempo, análises de regressão linear simples foram aplicadas visando encontrar relações funcionais significativas entre os parâmetros físico-químicos e o tempo de armazenamento. Através destas análises, foi possível observar que, embora os carvões apresentassem mudanças na capacidade de adsorção no decorrer do tempo, estas variações não impactaram na qualidade dos mesmos (índice de iodo e umidade). De modo geral, a variação nos índices de iodo e de umidade ao longo do tempo apresentada por todos os carvões avaliados não possui significância estatística, uma vez que os 
valores de $F_{\text {regressão }}<F_{\text {crítico }}$ e os valores de $p>0,05$, exceto para o carvão LA. Para as relações entre os índices de iodo e o tempo de armazenagem foram determinados valores de $F_{\text {regressão }}=1,53$ e de $p$ $=0,219$ para o carvão S630, de $F_{\text {regressão }}=1,14$ e de $p=0,289$ para o carvão W610ep, de $F_{\text {regressão }}=1,16$ e de $p=0,286$ para o carvão WU610, de $F_{\text {regressão }}=15,65$ e de $p=0,010$ para o carvão LA e para as relações entre os teores de umidade e o tempo de armazenagem valores de $F_{\text {regressão }}=3,310$ e de $p$ $=0,073$ para o carvão S630 e de $F_{\text {regressão }}=337,7$ e de $p=0,000$ para o carvão LA. O coeficiente de correlação de Pearson foi usado para medir o grau da correlação entre as duas variáveis avaliadas durante a armazenagem dos carvões, isto é, entre a umidade e o índice de iodo. A única amostra de carvão que apresentou uma correlação linear negativa significativa entre estas variáveis foi o carvão LA $(r=-0,600 ; p=0,010)$, indicando que o índice de iodo diminui conforme aumentam os teores de umidade do respectivo carvão. Para os demais carvões, correlações lineares não significativas foram observadas (para S630 $r=-0,06$; para W610ea, $r=0,14$; para W610ep, $r=-0,11$ e para WU610, $r=0,10$ ).

O carvão LA, por ser ácido e possuir menor granulometria, foi mais sensível à adsorção de umidade ao longo do tempo. Embora o carvão $S 630$ também seja ácido, o mesmo não apresentou diminuição significativa do índice de iodo no período avaliado. Este carvão (S630) apresenta maior granulometria, portanto, menor área de contato, com isso não foi sujeito a uma variação grande de umidade. As amostras W610ea, W610ep e WU610, não apresentaram aumento de umidade no decorrer do estudo, o que pode ser atribuído provavelmente ao seu caráter alcalino o que minimiza esse tipo de adsorção durante o armazenamento. A carga superficial dos carvões ativados depende principalmente da quantidade de heteroátomos presentes nos mesmos. Quando um material carbonáceo é imerso em uma solução aquosa, ele desenvolve uma carga de superfície que vem da dissociação de grupos de superfície ou da adsorção de íons da solução. A quantidade de oxigênio presente na superfície pode indicar a hidrofobicidade e a densidade eletrônica nas camadas de grafite. Uma carga negativa provém da dissociação de grupos contendo oxigênio, como grupos carboxílicos e fenólicos. A origem da carga superficial positiva é mais incerta e pode ser devido aos complexos de oxigênio superficial de caráter básico como pironas ou cromanos. Esses grupos apresentam um caráter mais hidrofóbico em relação aos grupos ácidos e com isso, a adsorção de água nos carvões básicos é menor do que nos carvões ácidos (MORENO-CASTILLA, 2004).

A Figura 1 apresenta o índice de iodo e o tempo de armazenamento de carvão com alto índice de acidez (LA e S630). Os resultados da análise de regressão linear para a amostra LA indicaram que a variação do índice de iodo durante o período avaliado foi significativa $\left(F_{\text {regressão }}\right.$ $=15,51 ; p=0,001)$. A diminuição do índice de iodo pode estar relacionada à maior variação de umidade do carvão amostrado, conforme foi possível observar durante o período avaliado (Figura 2). As moléculas de água preenchem os poros superficiais do carvão, diminuindo a eficiência de adsorção do iodo. Em vista deste comportamento pode-se utilizar a equação de reta prevista pela regressão linear entre o índice de iodo do carvão LA e o tempo de armazenamento para prever o tempo em que o referido carvão atingirá um valor de índice de iodo limite para sua comercialização e assim estabelecer com maior confiabilidade o prazo de validade deste. A equação de reta oriunda da análise de regressão linear é dada por Índice de Iodo $=824-0,370 \mathrm{x}$ dias. Em outras palavras, pode-se fazer uma previsão que um tempo de armazenagem igual a 605 dias será necessário para que o valor do índice de iodo do carvão LA seja igual ao valor limite de $600 \mathrm{mg} \mathrm{I}_{2} \mathrm{~g}^{-1}$ carvão. Todavia, essa previsão leva em consideração que durante o período previsto pelo modelo linear não há alteração na cinética de adsorção de iodo pelo carvão ativado. Estudos empíricos deveriam ser realizados para confirmar se o tempo previsto de 605 dias apresenta uma boa concordância com o tempo determinado experimentalmente antes de sua aplicação em ambiente industrial.

Já o carvão S630, por possuir granulometria maior, portanto, menor área de contato, está menos exposto à umidade e com isso não teve sua eficiência de adsorção, medida pelo índice de iodo, afetada de forma significativa durante o tempo de armazenamento do carvão $\left(F_{\text {regressão }}=1,53\right.$; $p=0,219)$. Sendo assim, pode-se sugerir que para este carvão o tempo de armazenamento será 
maior em comparação ao determinado para o carvão LA.

Figura 1 - Curvas do índice de iodo versus o tempo de armazenamento das amostras LA e S630.

Figure 1 - Iodine index curves versus the storage time of samples La and S630.

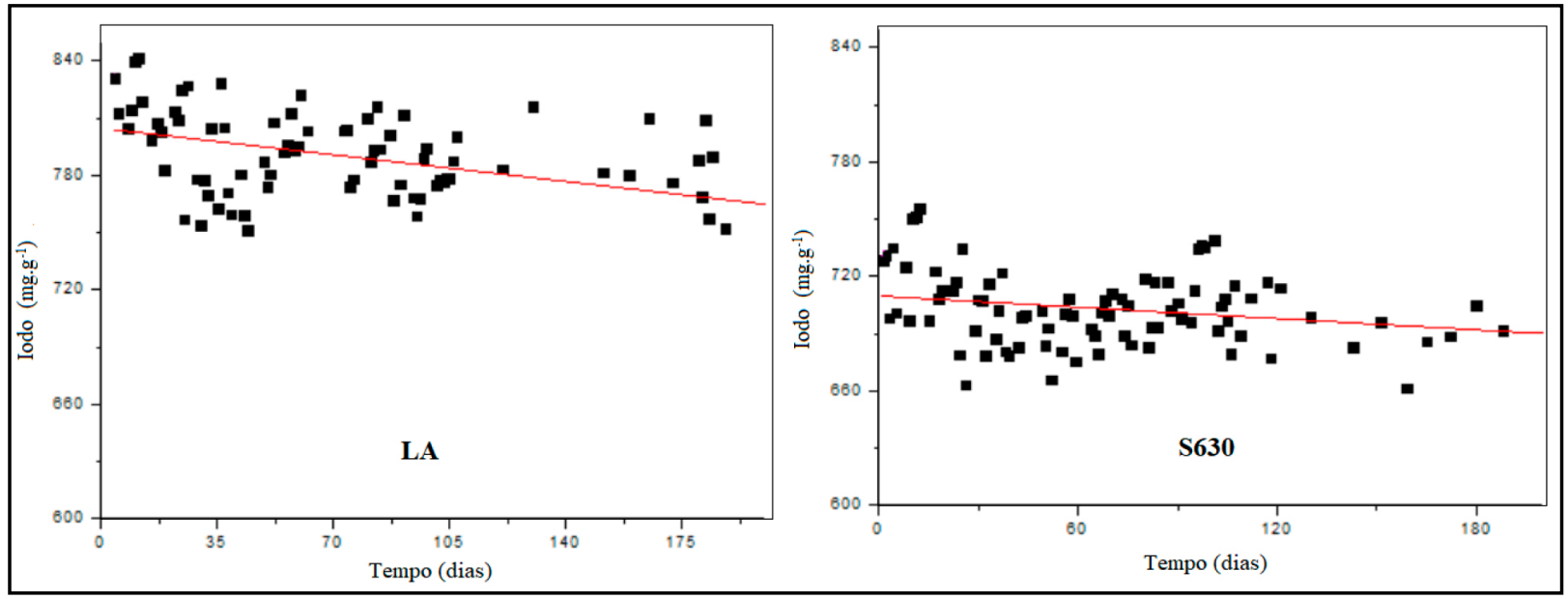

Fonte: Autores (2019)

Figura 2 - Variação da umidade nos carvões ativados com o decorrer do tempo de armazenamento.

Figure 2 - Variation of moisture in activated carbons over the course of storage time.

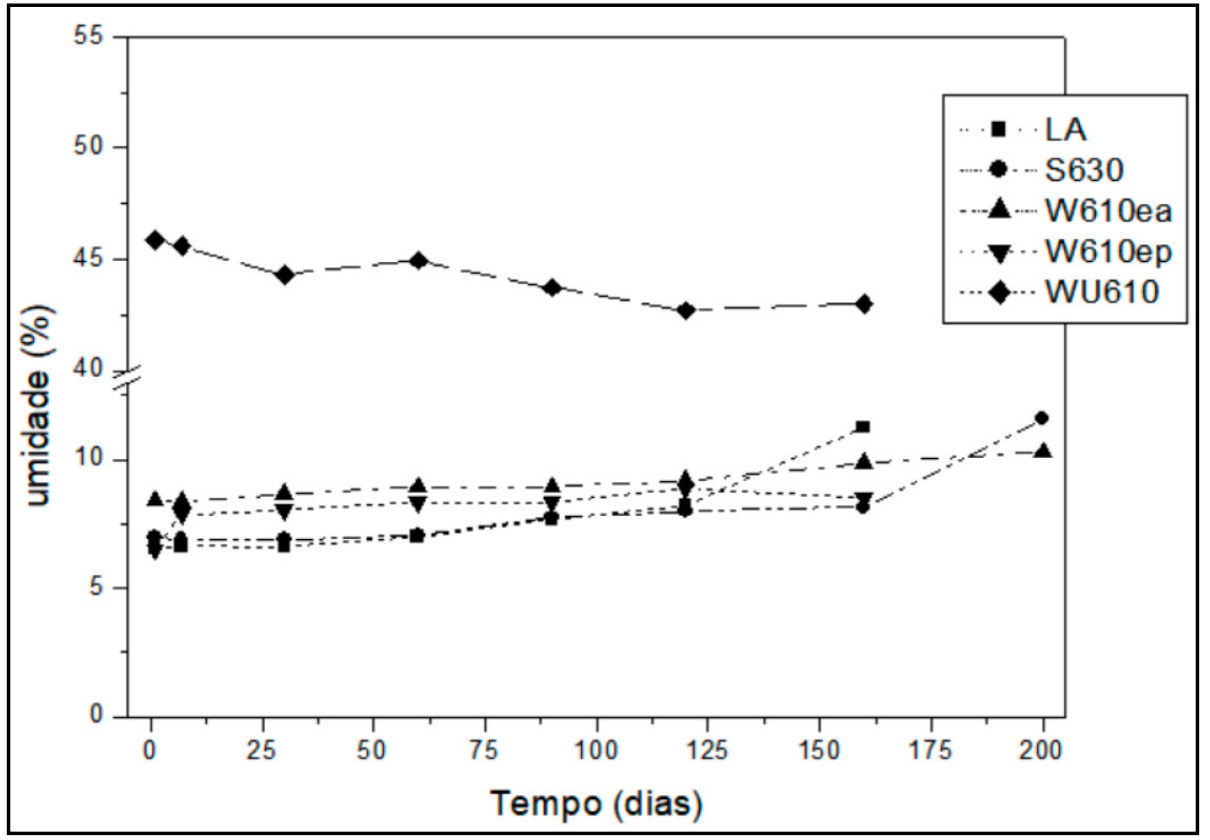

Fonte: Autores (2019)

Através dos resultados obtidos experimentalmente, supõe-se que a interação do carvão LA com a umidade do ar seja mais efetiva, o que o torna propenso a demonstrar um declínio maior em sua capacidade de adsorção caso este não seja armazenado adequadamente, uma vez 
que para realizar as análises se torna necessário à abertura do recipiente contendo o carvão, o que implicará numa interação maior do carvão com o ambiente que o cerca. No entanto, embora se observe um declínio no parâmetro índice de iodo para essa amostra, a mesma ainda está dentro do valor mínimo requerido para a comercialização do produto, pois o menor valor medido foi de $751,14 \mathrm{mg}$ de $\mathrm{I}_{2} \cdot \mathrm{g}^{-1}$ carvão. O carvão $\mathrm{S630}$, também ácido, não demonstrou variação significativa em sua capacidade de adsorção no decorrer dos dias avaliados (Figura 1). Apesar dessa amostra de carvão ter evidenciado uma grande variação nos teores de umidade (6,52 a 10,49 \%), a variação no índice de iodo permaneceu dentro dos parâmetros determinados para este tipo de carvão não afetando sua aplicabilidade, pois o menor valor medido foi de $661,56 \mathrm{mg} \mathrm{de} \mathrm{I}_{2} \cdot \mathrm{g}^{-1}$ carvão.

As amostras de carvão W610ea e W610ep apresentaram maior estabilidade durante o armazenamento, pois foi observado pelos resultados da regressão linear entre o índice de iodo e o tempo de armazenamento que estas não foram significativas (valores de $F_{\text {regressão }}<F_{\text {crítico }}$ e os valores de $p>0,05)$ e as retas oriundas da regressão apresentaram uma inclinação mínima, como é possível observar na Figura 3.

\section{Figura 3 - Curvas de regressão do índice de iodo versus o tempo de armazenamento das} amostras W610ea, W610ep e WU610 (produção: 2018).

Figure 3 - Regression curves of the iodine index versus the storage time of samples W610ea, W610ep and WU610 (production: 2018).

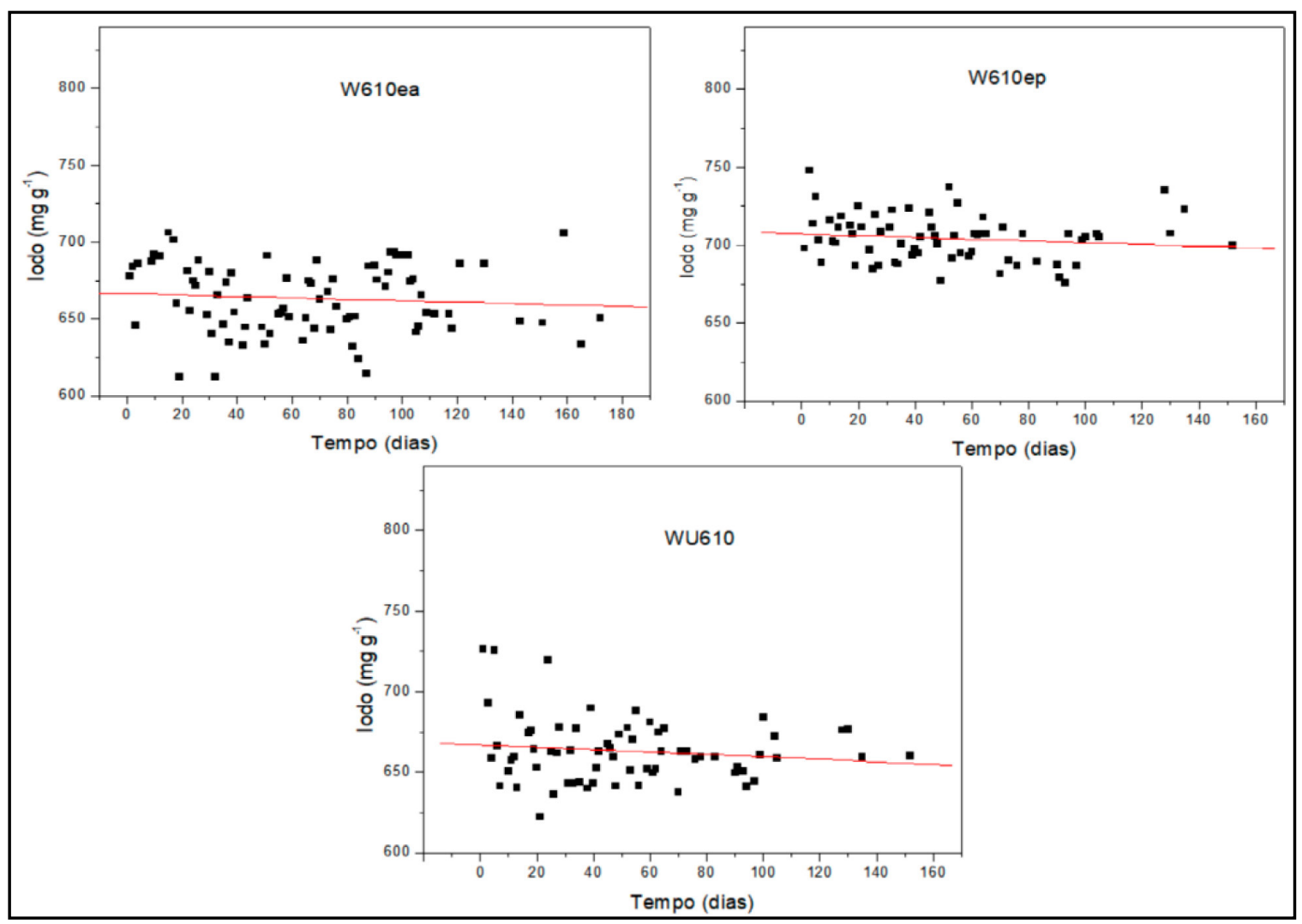

Fonte: Autores (2019)

No entanto, foi possível observar que a média dos teores de umidade obtida com o carvão W610ea $(9,04 \%)$ foi maior que a determinada pelo carvão W610ep (7,92 \%). Tal fato pode ser devido ao maior volume de amostra estocada na embalagem do carvão W610ep $(25 \mathrm{~kg})$ e ao ambiente onde 
o mesmo se encontra estocado, pois a presença de material particulado na atmosfera já atua como meio secante de umidade do ar, enquanto que a embalagem do carvão W610ea $(0,5 \mathrm{~kg})$, a cada vez que é aberta para amostragem, tem contato com o ar do laboratório que é mais úmido. Um teste- $t$ pareado foi aplicado a esses dados de umidade para os dois tipos de embalagem de armazenamento (potes plásticos de $0,5 \mathrm{~kg}$ e sacos duplos de papel-kraft com filme interno de polietileno de $25 \mathrm{~kg}$ ) e os resultados deste teste $\left(t_{o b s}=3,82 ; p=0,009\right)$ confirmaram que há uma diferença significativa existente entre os mesmos. Apesar desta diferença, o produto manteve-se com qualidade comercial durante o tempo de armazenamento avaliado. O carvão WU610 umectado, possui a característica única de ser antidispersivo do pó, importante para ambientes que necessitam estar isentos de poluição atmosférica. Este carvão não demonstrou variação significativa do índice de iodo e dos teores de umidade durante o tempo avaliado, conforme demonstrado na Figura 3. A curva de regressão linear do índice de iodo versus o tempo de armazenamento apresentada foi praticamente horizontal no gráfico e a variação dos teores de umidade foi mínima (entre 42,82 a 45,87 \%) pois, novamente os valores de $F_{\text {regressáo }}<F_{\text {crítico }}$ e os valores de $p>0,05$. Em vista destes resultados, fica bem evidente que os carvões de caráter alcalino são menos suscetíveis à adsorção de umidade durante o armazenamento, portanto, podem apresentar um tempo de prateleira superior aos carvões de caráter ácido. No entanto, vale ressaltar que dependendo da característica do carvão, um estudo do tempo de armazenagem deve ser realizado para garantir sua qualidade.

A Tabela 3 apresenta os valores médios, máximos e mínimos dos parâmetros índice de iodo e umidade para os carvões produzidos em 2017 (W610ep e WU610). Os gráficos contidos na Figura 4 apresentam a variação desses parâmetros medidos no mês da produção dos carvões e três medidas posteriores a um ano de armazenagem, totalizando 425 dias.

\section{Tabela 3 - Valores de índice de iodo e teores de umidade para as amostras de carvão ativado W610ep e WU610 (produção 2017, 425 dias de armazenamento).}

Table 3 - Iodine index values and moisture content for activated carbon samples W610ep and WU610 (2017 production, 425 days storage).

\begin{tabular}{ccccccc}
\hline Carvão & & \multicolumn{1}{c}{$\begin{array}{c}\text { Índice de iodo } \\
\left(\mathbf{m g ~ d e ~}_{\left.\mathbf{~} \cdot \mathbf{g}^{-1}\right)}\right.\end{array}$} & \multicolumn{3}{c}{$\begin{array}{c}\text { Umidade } \\
(\% \text { em massa })\end{array}$} \\
\hline & Média & Maior valor & Menor valor & Média & Maior valor & Menor valor \\
\hline W610ep & 501,61 & 515,97 & 489,27 & 11,03 & 12,80 & 9,05 \\
WU610 & 654,42 & 672,14 & 646,67 & 29,75 & 32,42 & 26,78 \\
\hline
\end{tabular}

Observou-se que não ocorreram perdas na eficiência de adsorção de iodo pelos carvões de base seca e umectado (Figura 4A), após 425 dias de produção. Quanto aos teores de umidade (Fig. 4B), somente o carvão de base seca apresenta um leve aumento nesse parâmetro, enquanto o umectado não se alterou, pois o mesmo já deve estar com sua superfície saturada com moléculas de água. Uma análise de regressão linear foi aplicada aos dados para verificar se havia uma diminuição significativa do índice de iodo ao longo do tempo avaliado o que poderia ter impacto na comercialização dos carvões. O carvão W610ep se mostrou relativamente estável ao longo do tempo de armazenamento. Este fato pode ser visualizado na Figura 4A e também pelos valores de $F_{\text {regressão }}$ que foram menores do que o valor de $F_{\text {crítico }}$ e pelos valores de $p>0,05$. Todavia, para o carvão WU610 foi observado que a regressão linear entre os valores de iodo e o tempo era significativa no nível de $95 \%$ de confiança, pois o valor de $F_{\text {regressão }}<F_{\text {crítico }}$ e o valor de $p<0,05$. Desta forma, é possível prever para este carvão o tempo que o mesmo pode ser estocado até atingir o valor limite de absorção de iodo considerando-se a equação da reta: índice de iodo = 
672 - 0,0582 x tempo, o que resulta em uma estimativa de tempo de armazenamento de 1237 dias, ou seja, aproximadamente três anos e quatro meses. Entretanto, vale ressaltar novamente, que a estimativa prevista pela equação de reta deve ser confirmada através de estudos empíricos antes de sua utilização em ambiente industrial.

Figura 4 - Variação do índice de iodo (A) e dos teores de umidade (B) nos carvões ativados WU610 e W610ep com o decorrer do tempo de armazenamento (425 dias).

Figure 4 - Variation of iodine content (A) and moisture content (B) in the activated charcoal WU610 and W610ep with the course of the storage time (425 days).

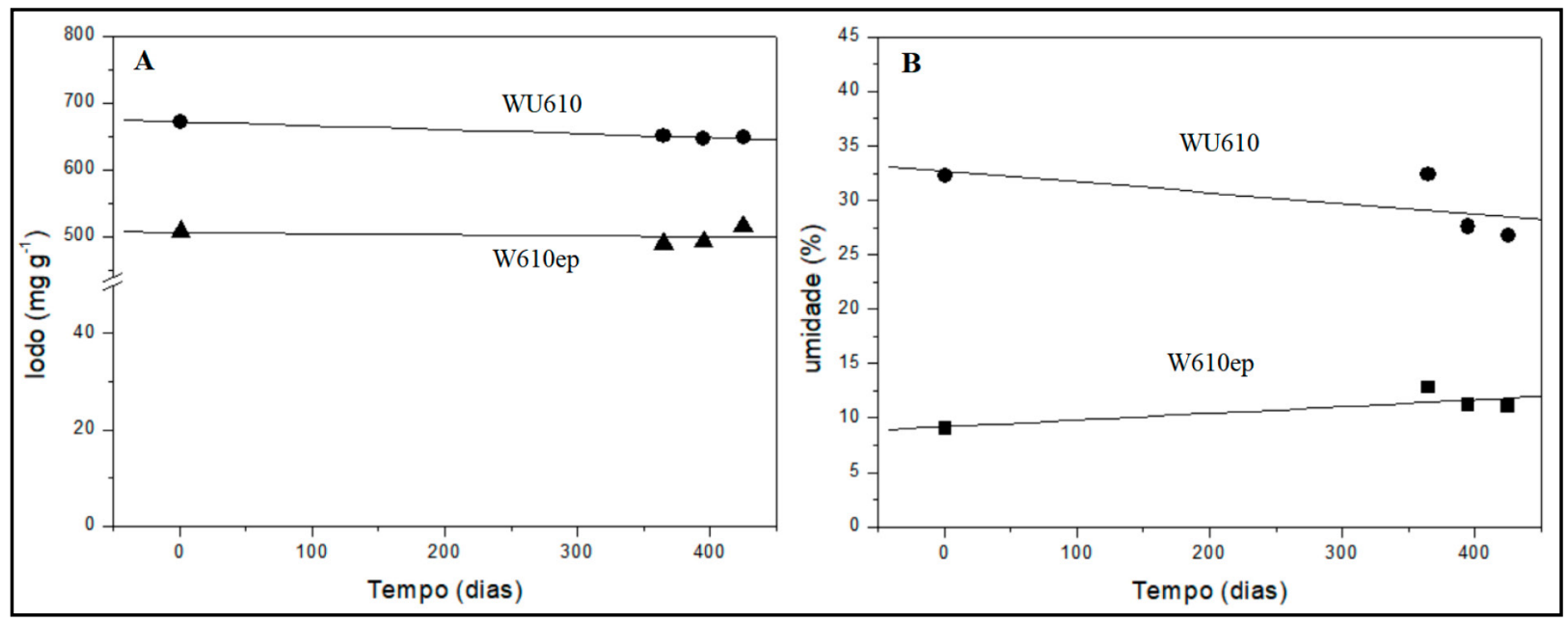

Fonte: Autores (2019)

\section{Conclusão}

Foi possível observar uma pequena variação na capacidade de adsorção dos carvões pulverizados LA e S630 com o passar do tempo. Este comportamento pode ser explicado pelo fato destes carvões apresentarem superfície ácida e maior afinidade pela água, entretanto, essa variação não interferiu na qualidade do produto, pois o índice de iodo permaneceu acima do valor mínimo exigido pela ABNT para comercialização. As amostras W610ep, W610ea e WU610, de superfícies alcalinas, foram as que apresentaram menor variação dos parâmetros medidos durante os meses avaliados. Esse estudo possibilitou garantir que o prazo de validade destes carvões abrange o período avaliado e que um controle da umidade do ambiente de estoque deste material pode garantir maior tempo de prateleira do produto comercial.

\section{Agradecimentos}

Agradecemos a empresa Alpha Carbo Industrial Ltda. pelo suporte financeiro e estrutura laboratorial para o desenvolvimento do projeto.

\section{Referências}

ABNT. ASSOCIAÇÃO BRASILEIRA DE NORMAS TÉCNICAS. Carvão ativado pulverizado Determinação do número de iodo - MB-3410. Rio de Janeiro, 1991a.

ABNT. ASSOCIAÇÃO BRASILEIRA DE NORMAS TÉCNICAS. MB-3414: Carvão ativado 
pulverizado - determinação da umidade. Rio de Janeiro, 1991 b.

ABNT. ASSOCIAÇÃO BRASILEIRA DE NORMAS TÉCNICAS. Carvão ativado pulverizado Especificação - EB-2133. Rio de Janeiro, 1991c.

ALLEN, S. J.; WHITTEN, L. The Production and Characterisation of Activated Carbons: A Review. Developments in Chemical Engineering and Mineral Processing, [s.1.], v. 6, n. 5, p. 231-261, 1998.

AWWA. Standart for Activated Carbon. ANSI/AWWAB600-96. 1996. Denver, Colorado.

DE ARRUDA, E.L.; DE ANDRADE, A. M.; JÚNIOR, A.F.D. Produção e ativação do carvão vegetal de três espécies florestais. Floresta, v. 47, n. 3, 2017.

DEIANA, A. C. et al. Use of grape must as a binder to obtain activated carbon briquettes. Brazilian Journal Chemical Engineering, [s.1.], v. 21, n. 4, p. 585-591, 2004.

EATON, A.D. et al. Standard methods for the examination of water and wastewater. American public health association, [s.1.], v. 21, p. 1600, 2005.

HUNG, Y. et al. Granular Activated Carbon Adsorption in: Physicochemical Treatment Processes. P. 573-633, Humana Press Inc. 2005. DOI. https://doi.org/10.1385/159259820x.

ISO. International Organization for Standardization. ISO 10523:2008, Water quality Determination of pH. 2008. https://www.iso.org/standard/51994.html .

KOSAKA, Koji et al. Removal of radioactive iodine and cesium in water purification processes after an explosion at a nuclear power plant due to the Great East Japan Earthquake. Water research, [s.1.], v. 46, n. 14, p. 4397-4404, 2012.

LIMA, L. S. et al. Characterization of activated carbons from different sources and the simultaneous adsorption of $\mathrm{Cu}, \mathrm{Cr}$, and $\mathrm{Zn}$ from metallurgic effluent. Separation and Purification Technology, [s.l.], v. 122, p. 421-430, 2014.

MORENO-CASTILLA, C. Adsorption of organic molecules from aqueous solutions on carbon materials. Carbon, [s.l.], v. 42, p. 83-94, 2004.

SHAMSUDDINA, M.S.; YUSOFFA, N.R.N.; SULAIMAN, M.A. Synthesis and characterization of activated carbon produced from kenaf core fiber using $\mathrm{H}_{3} \mathrm{PO}_{4}$ activation. Procedia Chemistry, [s.l.], v. 19, p. 558 - 565, 2016.

WEST, K. Carbon chemistry. Chelsea House Publishers. USA. 117 p. 2008.

YAKOUT, S.M.; SHARAF EL-DEEN, G. Characterization of activated carbon prepared by phosphoric acid activation of olive stones. Arabian Journal of Chemistry, [s.l.], v.9, p. S1155S1162, 2016. 